\title{
CHARACTERIZATION OF TITANIUM LASER WELDS
}

\author{
Hana ChmelíčKová ${ }^{a, *}$, Helena Hiklováa $^{a}$, LukÁŠ VÁClaVeK ${ }^{a}$, \\ JAN TOMÁŠTÍK ${ }^{b}$, RADIM ČTVRTLÍK ${ }^{c}$
}

a Joint Laboratory of Optics of Palacký University and Institute of Physics AS CR, Faculty of Science, Palacký University, 17. listopadu 12, 77146 Olomouc, Czech Republic

${ }^{b}$ Regional Centre of Advanced Technologies and Materials, Joint Laboratory of Optics of Palacký University and Institute of Physics AS CR, Faculty of Science, Palacký University, 17. listopadu 12, 77146 Olomouc, Czech Republic

${ }^{c}$ Institute of Physics of the Czech Academy of Sciences, Joint Laboratory of Optics of Palacký University and Institute of Physics AS CR, 17. listopadu 50a, 772 07 Olomouc, Czech Republic

* corresponding author: hana.chmelickova@upol.cz

\begin{abstract}
Butt welding of commercially pure titanium Grade 1 and Ti6Al4V alloy sheets using a pulsed Nd:YAG laser KLS 246 - 102 LASAG were carried out to determine optimal values of pulse energy and pulse length to create completely penetrated weld. Surface peak power density of about $3.10^{5} \mathrm{~W} . \mathrm{cm}^{-2}$ was found as an optimal value. Weld dimensions, both face width and penetration depth, are found to be proportional to increasing energy and decreasing pulse length. Gentle sagging and root penetration were revealed by means of contact surface profilometry. The nanohardness tests on transverse cross-sections detected approximately $50 \%$ higher hardness in the fusion zone than in the base material.
\end{abstract}

KEYworDs: Elasticity, laser welding, nanohardness, surface profile, titanium.

\section{INTRODUCTION}

The commercially pure titanium (CP Ti) and its alloys especially Ti6Al4V have good weldability. Gas tungsten arc welding (GTAW) and electron beam welding (EBW) are already used in wide range of applications in chemical, medical, nuclear and food industry, automotive and aerospace. Development of high-power laser sources has opened possibility to investigate methods of laser beam welding (LBW) that are more efficient, flexible and precise with localized heat affect to workpiece than conventional ones. Influence of laser beam parameters (power, pulse energy and frequency, scanning speed, spot diameter, focus position and shielding gas influence) on weld bead properties were examined in research laboratories all over the world. Badgar et al. investigated effect of heat input during welding of CP titanium by means of CW Nd:YAG laser on microstructure, microhardness, relative elongation, tensile and yield strength in Ref. [1. Lisiecki presented results of the disk laser welding of titanium alloy Ti6Al4V likewise in Ref. 22. Fomin et al. added filler to Ti6Al4V butt welds welded by means of $8 \mathrm{~kW}$ continuous-wave ytterbium fiber laser IPG and study influence of post welding heat treatment on microstructure, microhardness, residual stress distribution and fatigue performance (Ref. [3]). A significant influence of the laser welding high cooling rates to result weld mechanical properties was pointed out.

The objective of this paper was to characterize butt welds of CP titanium Gr.1 and Ti6Al4V alloy sheets, welded using a pulsed Nd:YAG laser KLS 246 - 102 LASAG under argon shielding gas atmosphere.

\section{EXPERIMENTAL SETUP}

Two sheets (40 mm x $12 \mathrm{~mm}$ ) of $0.8 \mathrm{~mm}$ thickness were fixed tightly on welding jig after cleaning by ethanol. The laser beam was focused by a $100 \mathrm{~mm}$ focusing lens, focus position $+3 \mathrm{~mm}$ was controlled by triangular laser system RIFTEK, spot diameter D in this position has the theoretic value of $0.84 \mathrm{~mm}$. Pulse frequency $13 \mathrm{~Hz}$ and linear axis speed $3 \mathrm{~mm} . \mathrm{s}^{-1}$ were set according to previous parameter optimization to ensure laser spot overlap $67 \%$. High purity argon was guided in laser beam axis with flow rate of 12 l. $\mathrm{min}^{-1}$. The influence of increasing pulse energy $\mathrm{E}$ at constant pulse length $3 \mathrm{~ms}$ on welding width and penetration depth was investigated with CP titanium sheets. Pulse energy value was gradually set to $2.63 \mathrm{~J}$, $3.15 \mathrm{~J}, 3.72 \mathrm{~J}, 4.33 \mathrm{~J}, 5.03 \mathrm{~J}$ and $5.58 \mathrm{~J}$, butt weld was created for each of these pulse energies. The influence of increasing pulse length $t_{p}$ at constant pulse energy $5.03 \mathrm{~J}$ on welding penetration depth was investigated with Ti6Al4V alloy. Pulse length was gradually set to $2.0 \mathrm{~ms}, 2.5 \mathrm{~ms}, 3.0 \mathrm{~ms}, 3.5 \mathrm{~ms}, 4.0 \mathrm{~ms}, 4.5 \mathrm{~ms}$. $5.0 \mathrm{~ms}$ and $5.5 \mathrm{~ms}$, butt weld was created for each pulse length. Change of the pulse energy E or pulse length $t_{p}$ leads to a change of the peak power $\mathrm{P}_{\text {peak }}$ as well as to its surface density $\mathrm{Q}_{\text {Ppeak }}$ that is an important processing parameter. Surface area $\mathrm{S}$ is dependent on laser spot diameter D, see Equation 1

$$
\mathrm{Q}_{\text {Ppeak }}=\mathrm{P}_{\text {peak }} \cdot S^{-1}=4 E \cdot\left(\pi \mathrm{D}^{2} \cdot \mathrm{t}_{\mathrm{p}}\right)^{-1}
$$




\section{Methods}

The weld width both on the top and the bottom specimens' surfaces were imaged and measured by means of laser scanning confocal microscope LEXT 5000. The penetration depth, heat affected zone depth and weld macrostructure were evaluated on the samples' transverse cross-sections that were etched by Kroll's agent after grinding and fine polishing procedure. Surface profile in fifty points per millimeter in (4 $\mathrm{x} 4 \mathrm{~mm}^{2}$ area around weld bead was measured by contact profilometer TALYSURF. Graphs of 200 surface profiles and 3D axonometric display were created in TALYMAP (Ref. 4]) to measure and visualize sagging or overlap of fusion zone, as well as the root width and the root penetration under the sample back side plane. Mechanical properties of the fully penetrated welds were determined by means of nanohardness tests on the transverse cross-sections. Nano indentation instrument NanoTest NTX, (Micro Materials, UK) was used. Hardness and elastic modulus were determined by nanoindentation with a pyramidal diamond Berkovich tip at maximal load $50 \mathrm{mN}$ (Ref. [5). Set of 8 lines in horizontal direction each with 17 points with spacing $100 \mu \mathrm{m}$ creates a matrix that covered base material (BM), heat affected zone (HAZ) and fusion zone (FZ). The nanoindentation curves were evaluated by Oliver-Pharr method for hardness and reduced elastic modulus determination. The indenter tip calibration was performed using the fused silica sample.

\section{Results And Discussion}

\subsection{Dimensions DePEndenCE ON ENERGy, PULSE LENGTH AND PEAK POWER DENSITY}

Average values of weld face fusion zone width (FZW) and root width (RW) together with fusion zone penetration depth (FZPD) of not fully penetrated welds are summarized in Table 1 for CP titanium samples, welded with constant pulse length of $3 \mathrm{~ms}$ and increasing pulse energy. Weld dimensions grew up with increasing pulse energy. Full penetration without significant surface defects was achieved with energy 5.03 J and peak power surface density $\mathrm{Q}_{\text {Ppeak }}=3.10^{5} \mathrm{~W}$. $\mathrm{cm}^{-2}$. Magnified view of this weld face shows distinctly overlapped laser spots (Figure 1) and unbroken complete root (Figure 2). Higher energies led to deep sagging of fusion zone or melt pool collapse. Measurement of Ti6Al4V alloy samples welded with constant pulse energy of $5.03 \mathrm{~J}$ and increasing pulse length denoted the same trend. The best fully penetrated weld was achieved for a pulse length of $3 \mathrm{~ms}$. Shorter pulse length $2.5 \mathrm{~ms}$ and $2 \mathrm{~ms}$ with the same energy resulted in a higher peak power surface density that in turn led to an appreciable weld bead sagging. Penetration depth decreased with pulse prolongation from $3.5 \mathrm{~ms}$ to $5.5 \mathrm{~ms}$ and the penetration welding mode transformed to the heat conduction one.

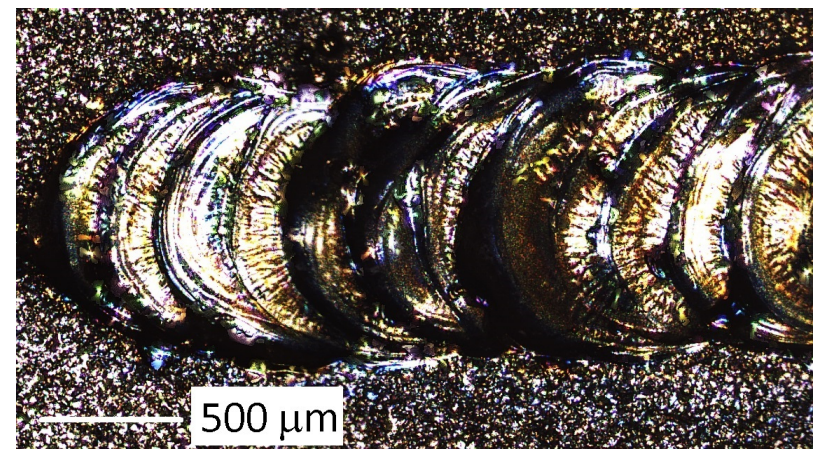

Figure 1. A view of $\mathrm{CP}$ titanium weld face $(\mathrm{E}=$ $\left.5.03 \mathrm{~J}, \mathrm{t}_{\mathrm{p}}=3 \mathrm{~ms}\right)$.

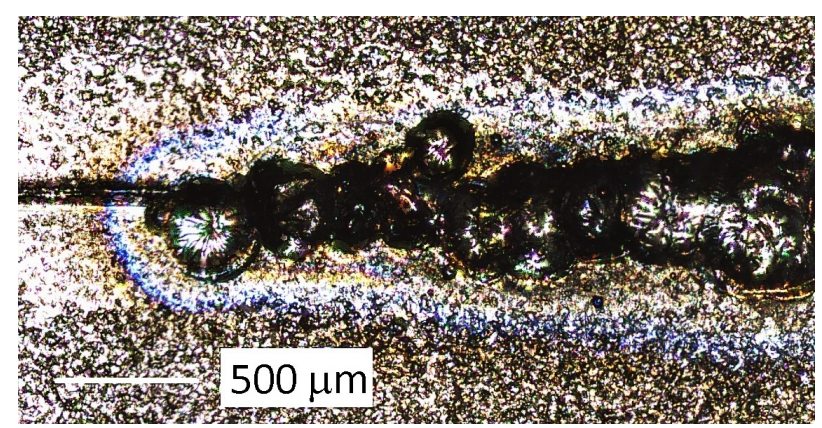

Figure 2. A view of $\mathrm{CP}$ titanium weld $\operatorname{root}(\mathrm{E}=$ $\left.5.03 \mathrm{~J}, \mathrm{t}_{\mathrm{p}}=3 \mathrm{~ms}\right)$.

\begin{tabular}{lllll}
\hline $\begin{array}{l}\mathrm{E} \\
(\mathrm{J})\end{array}$ & $\begin{array}{l}\text { QPpeak } \\
\left(\mathrm{W} . \mathrm{cm}^{-2}\right)\end{array}$ & $\begin{array}{l}\text { FZW } \\
(\mathrm{mm})\end{array}$ & $\begin{array}{l}\text { FZPD } \\
(\mathrm{mm})\end{array}$ & $\begin{array}{l}\text { RW } \\
(\mathrm{mm})\end{array}$ \\
\hline 2.63 & $1.56 .10^{5}$ & 0.77 & 0.11 & \\
3.15 & $1.89 .10^{5}$ & 0.70 & 0.17 & \\
3.72 & $2.23 .10^{5}$ & 0.93 & 0.32 & \\
4.33 & $2.59 .10^{5}$ & 0.99 & 0.51 & \\
5.03 & $3.01 .10^{5}$ & 1.07 & & 0.54 \\
5.58 & $3.37 .10^{5}$ & 1.09 & & 0.82 \\
\hline
\end{tabular}

TABLE 1. Weld dimensions dependence on increasing energy for CP titanium samples.

\subsection{Surface PROFILE}

Average sagging of $50 \mu \mathrm{m}$ is seen in the 3D axonometric display of CP titanium weld face (Figure 3), welded with $\mathrm{Q}_{P_{\text {peak }}}$ of about $3 \cdot 10^{5} \mathrm{~W} \cdot \mathrm{cm}^{-2}$. Periodic alternation of peaks and depressions on the longitudinal weld profile is caused by the overlap of laser pulse spots, average distance between these points is about $130 \mu \mathrm{m}$. A set of 200 transverse profiles measured in $4 \mathrm{~mm}$ section over the weld root (energy $5.03 \mathrm{~J}$, pulse length $3 \mathrm{~ms}$ ) for the Ti6Al4V alloy is displayed in Fig. 4. The root penetration also alternated regularly with the laser spot overlap, maximal value didn't exceed $90 \mu \mathrm{m}$, while minimal value is situated close to the sample surface plane. The occasional occurrence of spatters on the sample surface was also detected for welds made with higher surface power densities. 


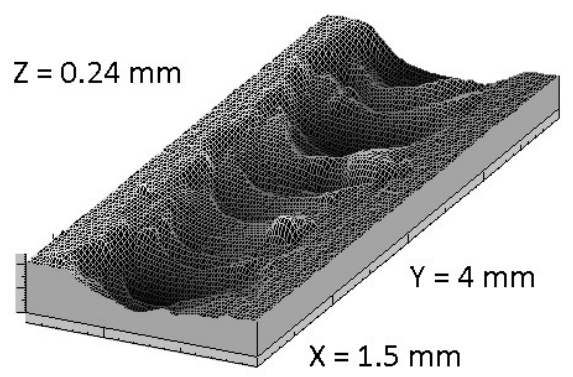

Figure 3. 3D axonometric display of $\mathrm{CP}$ titanium weld face $\left(\mathrm{E}=5.03 \mathrm{~J}, \mathrm{t}_{\mathrm{p}}=3 \mathrm{~ms}\right)$.

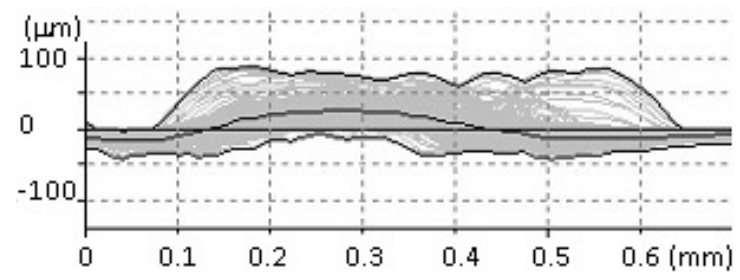

Figure 4. A set of 200 surface profiles of Ti6Al4V alloy weld $\operatorname{root}\left(\mathrm{E}=5.03 \mathrm{~J}, \mathrm{t}_{\mathrm{p}}=3 \mathrm{~ms}\right)$, with the highlighted maximal, average and minimal profiles.

\subsection{NANOHARDNESS TEST}

Matrix of 17 nanohardness values in horizontal and 8 values in vertical direction was taken from Ti6Al4V sample transverse cross-section with step $100 \mu \mathrm{m}$. The average hardness value of base material was found to be $2.9 \mathrm{GPa}$. The individual values varied from 2.3 GPa to 3.1 GPa. The coarse-grained fusion zone possessed an average hardness of $4.3 \mathrm{GPa}$, varying from minimum 3.4 $\mathrm{GPa}$ to maximum 5.8 GPa. This means that the fusion zone is approx. $48 \%$ harder than the base material. Heat affected zone between fusion zone boundary and the base material exhibits average hardness of 3.6 GPa. The nanohardness distribution in three selected horizontal matrix rows, measured in distance $100 \mu \mathrm{m}, 400 \mu \mathrm{m}$ and $700 \mu \mathrm{m}$ from the weld face (Figure 5), is shown in Fig. 6.

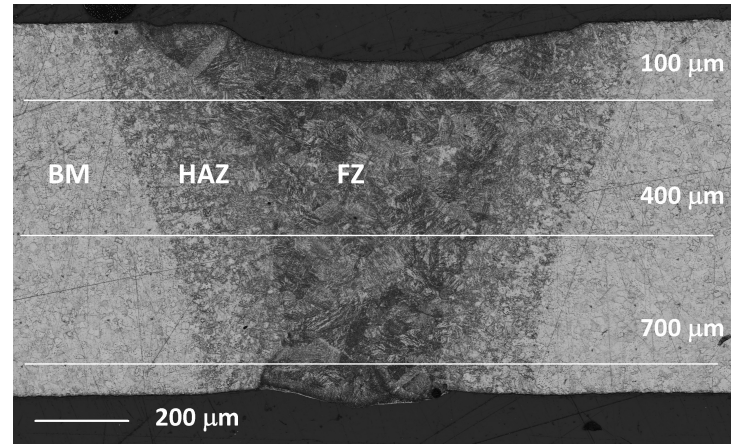

FiguRE 5. Macrograph of the transverse cross-section of Ti6Al4V butt weld $\left(\mathrm{E}=5.03 \mathrm{~J}, \mathrm{t}_{\mathrm{p}}=3 \mathrm{~ms}\right)$, with the visible boundaries between fusion zone (FZ), heat affected zone (HAZ) and base material (BM). White lines mark nanohardness data used in graph (Figure 6).

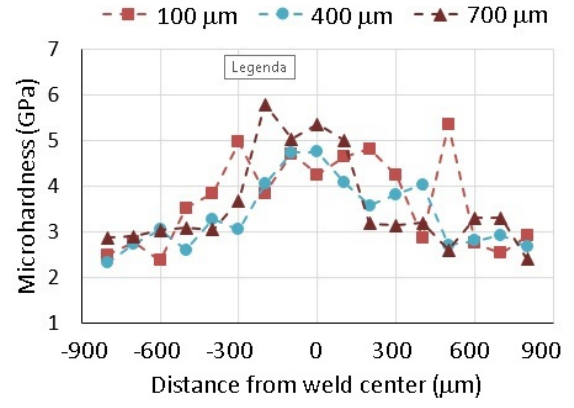

FIGURE 6. Nanohardness profiles on the transverse cross-section of Ti6Al4V butt weld $\left(\mathrm{E}=5.03 \mathrm{~J}, \mathrm{t}_{\mathrm{p}}=\right.$ $3 \mathrm{~ms}$ ) in the distance $100 \mu \mathrm{m}, 400 \mu \mathrm{m}$ and $700 \mu \mathrm{m}$ from the weld face.

In a similar way, matrix of 17 nanohardness values in horizontal and 7 values in vertical direction was taken from CP titanium sample transverse crosssection with step $100 \mu \mathrm{m}$ (Figure 7). Full penetration was achieved here with the same parameters as in case of Ti6Al4V alloy $\left(\mathrm{E}=5.03 \mathrm{~J}, \mathrm{t}_{\mathrm{p}}=3 \mathrm{~ms}\right)$. The average nanohardness value of the base material was found to be $2.5 \mathrm{GPa}$, varying from $2.1 \mathrm{GPa}$ to $2.9 \mathrm{GPa}$. The fusion zone with coarse elongated grains has average hardness of $4.2 \mathrm{GPa}$, varying from $3.4 \mathrm{GPa}$ to $5.5 \mathrm{GPa}$, it means about $70 \%$ more than hardness of the base material. Heat affected zone with visible boundaries with the base material and fusion zone exhibits average nanohardness of 3.1 GPa.

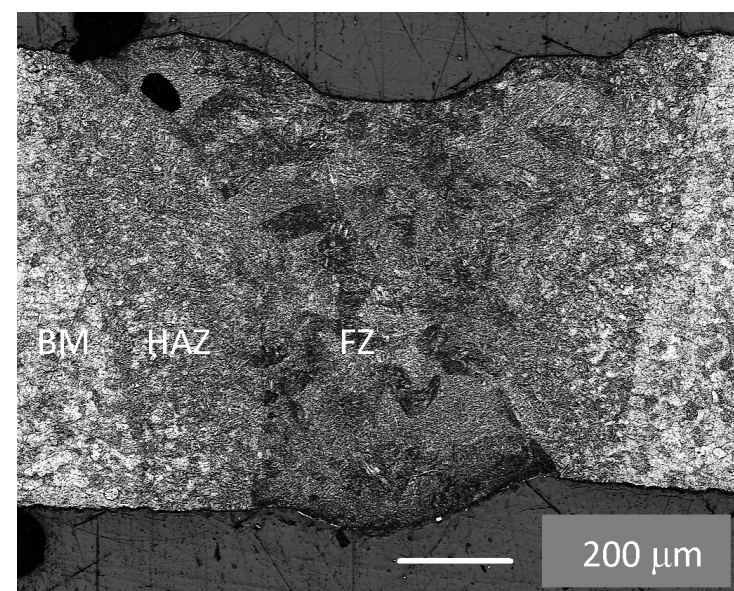

FiguRE 7. Macrograph of the transverse cross-section of $\mathrm{CP}$ titanium butt weld $\left(\mathrm{E}=5.03 \mathrm{~J}, \mathrm{t}_{\mathrm{p}}=3 \mathrm{~ms}\right)$ with the visible boundaries between fusion zone (FZ), heat affected zone (HAZ) and base material (BM).

The nanohardness distribution across the whole measured area of CP titanium sample transverse cross-section is displayed in Figure 8 . Values around $5.5 \mathrm{GPa}$ have occurred sporadically, mostly close to weld centerline. Although the $\mathrm{CP}$ titanium base material has a lower hardness than the Ti4Al6V alloy, the average hardness of both fusion zones is almost the same and is around $4.2 \mathrm{GPa}$. Due to fast heating over titanium melting temperature and high cooling 
rates, that is characteristic phenomenon of laser welding, metastable phases can be formed, such as alfa martensite (Ref. [1]).

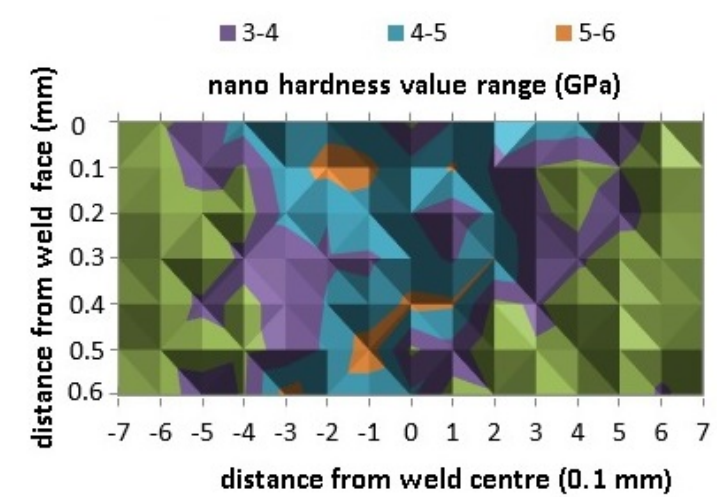

Figure 8. Surface graph of nanohardness matrix covering area of $1.4 \mathrm{~mm} \times 0.6 \mathrm{~mm}$ on the transverse cross-section of CP titanium butt weld $(\mathrm{E}=5.03 \mathrm{~J}$, $\left.\mathrm{t}_{\mathrm{p}}=3 \mathrm{~ms}\right)$.

\subsection{ReDUCED ELASTiC MODULUS AND ELASTIC RECOVERY PARAMETER}

In contrast to hardness, there are no evident differences between reduced elastic modulus $\mathrm{E}_{\mathrm{r}}$ values of base material and fusion zone. The average reduced modulus value for Ti6Al4V alloy is $136 \mathrm{GPa}$, thought values from $113 \mathrm{GPa}$ to $157 \mathrm{GPa}$ were occasionally observed across the measurement area. The CP titanium sample has an average value of $\mathrm{E}_{\mathrm{r}}=141 \mathrm{GPa}$, with few extremes varying from $110 \mathrm{GPa}$ to $166 \mathrm{GPa}$, which were all situated in the fusion area. This may reflect the local inhomogeneity of the weld macrostructure (Figure 9).

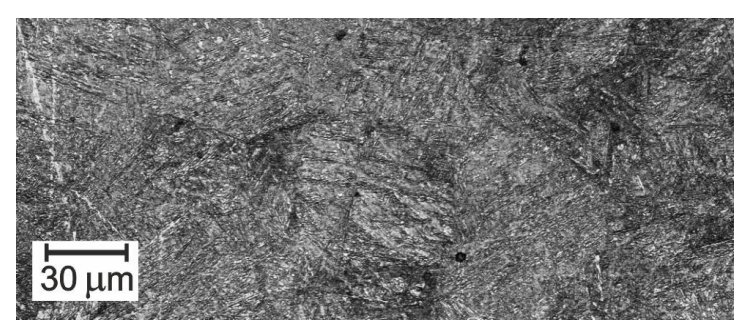

Figure 9. Detail of CP titanium weld fusion zone.

\section{Conclusions}

Optimal parameters for fully penetrated butt weld for CP titanium Gr.1 and Ti6Al4V alloy sheets with thickness $0.8 \mathrm{~mm}$ were found during welding experiments on pulsed Nd:YAG laser, which are the pulse energy of about $5 \mathrm{~J}$ and the pulse length $3 \mathrm{~ms}$ for laser spot diameter of $0.84 \mathrm{~mm}$. The average sagging of $50 \mu \mathrm{m}$ and the root penetration of $90 \mu \mathrm{m}$ were measured by means of contact profilometer that also revealed a wavy profile of remelted material in longitudinal weld direction. Dimensions of the fusion and heat-affected zone were measured on the weld transverse cross-sections, where these values growth with increasing surface peak power density. The weld face of optimal welds has width about $1 \mathrm{~mm}$, while root width is two times smaller, about $0.5 \mathrm{~mm}$. The coarsegrained fusion zone of Ti6Al4V alloy shows an average hardness value of $4.3 \mathrm{GPa}$ with maximum of $5.8 \mathrm{GPa}$, similarly the fusion zone with coarse elongated grains of CP titanium optimal sample has average hardness value of $4.2 \mathrm{GPa}$ with maximum of $5.5 \mathrm{GPa}$. Analysis of reduced elastic modulus values did not reveal evident differences between the base material and the fusion zone.

\section{ACKNowledGements}

The authors gratefully acknowledge the support by the Operational Program Research, Development and Education, project no. CZ.02.1.01/0.0/0.0/17_049/0008422 of the Ministry of Education, Youth and Sports of the Czech Republic, the project IGA_PrF_2019_008 of Palacký University and the project TH03020245 of the Technology Agency of the Czech Republic.

\section{REFERENCES}

[1] D. Badkar, K. Pandey, G. Buvanashekaran. Effects of laser phase transformation hardening parameters on heat input and hardened-bead profile quality of unalloyed titanium. Transactions of Nonferrous Metals Society of China 20(6):1078 - 1091, 2010. DOI:10.1016/S1003-6326(09)60261-2

[2] A. Lisiecki. Laser welding of titanium alloy Ti6Al4V using a disk laser. MTM J 7:53-56, 2012.

[3] F. Fomin, V. Ventzke, F. Dorn, et al. Effect of microstructure transformations on fatigue properties of laser beam welded Ti-6Al-4V butt joints subjected to postweld heat treatment. In T. Tanski, W. Borek (eds.), Study of Grain Boundary Character, chap. 6. IntechOpen, Rijeka, 2017. DOI:10.5772/66178

[4] H. Hiklová, H. Chmelíčková, M. Havelková, L. Řiháková. Using the contact profilometer to measure the dimensional changes of metal samples after laser treatment. In NDE for Safety 2013 / Defektoskopie 2013, pp. 39-44.

[5] L. Václavek, J. Tomaštík, L. Nožka, R. Čtvrtlík. Physical characterization of hafnium oxide thin films annealed in vacuum. In Local Mechanical Properties XIII, vol. 784 of Key Engineering Materials, pp. 135-140. Trans Tech Publications Ltd, 2018. DOI:10.4028/www.scientific.net/KEM.784.135 